\title{
Near term mitigation policy for global change under uncertainty: Minimizing the expected cost of meeting unknown concentration thresholds
}

\author{
Gary Yohe ${ }^{\mathrm{a}}$ and Rodney Wallace ${ }^{\mathrm{b}}$ \\ aepartment of Economics, Wesleyan University, Middletown, CT06459, USA \\ E-mail:gyohe@wesleyan.edu \\ 'Department of Economics, University of Michigan, Ann Arbor, MI 48109, USA
}

Received 25 August 1995; revised 20 December 1995

\begin{abstract}
An aggregate integrated assessment model is used to investigate the relative merits of hedging over the near term against the chance that atmospheric concentrations of carbon dioxide will be limited as a matter of global policy. Hedging strategies are evaluated given near term uncertainty about the targeted level of limited concentrations and the trajectory of future carbon emissions. All uncertainty is resolved in the year 2020, and strategies that minimize the expected discounted value of the long term cost of abatement, including the extra cost of adjusting downstream to meet unexpected concentration limits along unanticipated emission trajectories, are identified. Even with uncertainties that span current wisdom on emission futures and restriction thresholds that run from $550 \mathrm{ppm}$ through $850 \mathrm{ppm}$, the results offer support for at most modest abatement response over the next several decades to the threat of global change.
\end{abstract}

\section{Introduction}

Armed with a preliminary but growing understanding of the potential damage that might result from greenhouse warming, researchers have begun systematically to weigh the potential benefits of emissions abatement strategies against their anticipated cost. Sixteen of the twenty-three distinct integrated assessment models identified in the most recent report of Working Group III of the Intergovernmental Panel on Climate Change [4] are designed to do just that; and most of them base their results on specifications of damage functions that typically associate a $2.5^{\circ} \mathrm{C}$ increase in temperature with losses on the order of $1.3 \%$ to $2 \%$ of world GDP ${ }^{1}$. These research efforts will continue, but it is becoming increasingly clear that they will do so in the context of a growing list of careful analyses of market-based damages that suggest that earlier cost estimates for advanced economies may be severely exaggerated.

Yohe et al. [18], for example, recently reported that the likely transient opportunity cost of greenhouse induced sea level rise associated in the United States with a $2.5^{\circ} \mathrm{C}$ temperature increase by 2065 lies between $\$ 72$ and $\$ 139$ million along the now most likely $33 \mathrm{~cm}$ trajectory - an estimate that is roughly one-tenth the $\$ 1$ billion reported by, among others, Cline [1]. In light of

1 Sce tables 1 through 4 of Chapter 10 in Weyant et al. [12] for a complete list of these models and some brief description of each entry. this and other studies, some researchers have begun to argue that estimates of market-based damages are falling so fast that it is now difficult to see how they will sum ultimately to anything that is significantly greater than zero $^{2}$; and if this perception is accurate, then integrated assessment modelers will soon be forced to build the benefit side of their evaluation of mitigating policy options entirely from estimates of nonmarket damages.

The work reported here takes this insight at face value, but it also recognizes that valuation techniques for nonmarket damages are controversial and have not yet been applied widely to global change impacts. It also recognizes concerns raised by many researchers that the cost-benefit paradigm is ill-equipped to handle both the possibility of irreversible impacts and the intergenerational welfare comparisons that lie at the heart of their view of the global change problem. Rather than wait new techniques to emerge that buttress the paradigm and aid its application to global change, this work recognizes the real possibility that decisions about abatement policies may actually be founded on something other

2 William Nordhaus, for example, argued this point before the January 1995 meeting of the American Economic Association. Thomas Schelling has held this view for some time, and articulated it yet again during an intervention at the latest meeting of the International Energy Workshop in Vienna in June of 1995. Results from an impacts analysis conducted for the United States with the support of the Electric Power Research Institute will likely show several potentially positive effects when change is cast in light of a future that allows for adaptation. 
than efficiency criteria of even an expanded cost-benefit calculus. It assumes, instead,

(1) that significant nonmarket and/or irreversible impacts will be identified at a date certain in the future (taken to be the year 2020 in what follows),

(2) that these impacts will be triggered when atmospheric concentrations of carbon dioxide cross a specific threshold that is unknown at present but which will be revealed at the same future date (distributed in this work between 550 and $850 \mathrm{ppm}$ ), and

(3) that global decision-makers will decide for some reason that the revealed impact concentration threshold will not be crossed as a matter of policy regardless of cost.

It should be emphasized from the start that highlighting concentration thresholds is not really what sets this work apart from earlier analyses. Limiting concentration thresholds are offered simply to illustrate a sort of "single number fixation" from which policies frequently emerge and to emphasize that the critical policy threshold may or may not emerge from an efficiency driven economic perspective. Regardless of its source, that it might emerge and that its value is presently uncertain puts the question of deciding near term abatement strategy into a new context - one of hedging or buying insurance now against the excessive cost of reacting late to a future constraint that could be very binding.

The hedging tradeoff to be explored is easily described when the representative focus on concentration thresholds is adopted. Policies would have to be crafted to reduce carbon emissions if a threshold were identified in the future, but the delay in its resolution does not necessarily relieve decision makers of the burden of making some sort of near term response to its possibility. The issue that faces them at the end of the 20th century is therefore one of what to do while the uncertainty is being resolved. Set early carbon taxes (e.g.) too high over the next 25 years, for example, and emissions will be overly restricted in the short term. Controls could be relaxed later, of course, but the resulting distant cost savings would not necessarily cover all of the near term expense. Set early taxes too low, however, and costly "catch-up" policies would be required in the next century. Present day decision makers must thus decide the degree to which interim emissions should be reduced so that the expected value of the discounted sum of control costs might be minimized.

Economic efficiency will, therefore, not be ignored; it will, instead, be imposed upon the intertemporal design of policy so that investment in meeting its target will have the smallest possible effect on the global economy. The key word, here, is "investment". Since cost incurred in the near term is an "investment" designed to reduce the future cost of meeting a specified policy objective, the potential social benefits of meeting that objective are irrelevant. The relative efficacy of hedging with an abatement policy (given that the policy is not irreversible) should be judged in exactly the same way that any such investment project is evaluated under uncertainty - on the basis of the present value return (savings, in this case) of net cost and discounted at the real rate of return of private capital ${ }^{3}$.

Since this is the debut of the Connecticut (YOHE) Model, many of its details are described briefly in the next section. Readers familiar with the integrated assessment literature will quickly see it as a marriage of the original Nordhaus-Yohe [10] probabilistic-scenario model with the more recent DICE model authored by Nordhaus [9] alone. Section 3 follows with not only a description of the sources of uncertainty built into the Connecticut Model, but also a description of seven representative scenarios that have been chosen to reflect its range of variability in carbon emission trajectories. Preliminary concentration limits and the associated near term carbon tax trajectories that solve the decision makers' immediate policy dilemma are identified for each representative scenario in section 4 before uncertainty over the range of emission scenarios is confronted in section 5 .

Despite a wide range of possible futures that spans current conventional wisdom and no presumed a priori information about which threshold will ultimately be chosen, section 5 reports a robust result for the specific short term hedging question posed here: the expected discounted value of long term control costs is minimized by imposing no tax (or small taxes) on carbon for the assumed 25 years that it will take to (1) pick the correct threshold and (2) identify the scenario that most accurately depicts the future.

\section{The Connecticut (YOHE) Model: an aggregate integrated model with energy}

World economic output in any year $t$ [the standard GDP denoted here by $X(t)]$ is taken to be functionally related to the capital stock $[K(t)]$, the size of population $[L(t)]$, and the consumption of fossil and nonfossil fuel [ $E_{c}(t)$ and $E_{n}(t)$, respectively] according to

$$
\begin{aligned}
x(t)= & \Omega(t) A(t) K(t)^{\gamma}\left\{L ( t ) ^ { d ( t ) } \left[b E_{c}(t)^{\alpha}\right.\right. \\
& \left.\left.+(1-b) E_{n}(t)^{\alpha}\right]^{(1-d(t)) / \alpha}\right\}^{1-\gamma},
\end{aligned}
$$

so that the elasticity of substitution between fossil and nonfossil fuel $\left[\sigma_{c n}\right]$ is given by $[1 /(\alpha-1)]$. The share of output devoted to paying labor will change over time so that equation (2.1) can be adjusted each year to approximate a more general constant elasticity of substitution

3 See, e.g., Dixit and Pindyck [2]. 
production structure with a series of evolving CobbDouglas schedules. More specifically (see Yohe [15]), letting the share of output devoted to labor vary over time according to

$$
d(t)=\left[\left(k_{2} P(t)^{[q /(q-1)]}+1\right]^{-1},\right.
$$

with

$$
k_{2}=[(1-m) / m]^{[1 /(q-1)]},
$$

supports a general CES structure of the form

$$
x=A K^{\gamma}\left[m L^{q}+(1-m) E^{q}\right]^{(1-\gamma) / q} .
$$

Of course, the initial share of labor is

$$
d(0)=\left[\left(k_{2} P(0)^{|q /(q-1)|}+1\right]^{-1} .\right.
$$

As a result, the effective elasticity of substitution over time between labor $[L(t)]$ and energy $\left[E(t) \equiv E_{c}(t)\right.$ $\left.+E_{n}(t)\right]$, denoted $\sigma_{E L}$, is given by $[1 /(q-1)]$ even though the production structure for any one year has $\sigma_{E L}=-1$. Note, in passing, that

$$
P(t) \equiv\left\{\left[P_{c}(t) E_{c}(t)+\left(P_{n}(t) E_{n}(t)\right] /\left[E_{c}(t)+E_{n}(t)\right]\right\}\right.
$$

is the (weighted) average price of energy given the prices of fossil and nonfossil fuels $\left[P_{c}(t)\right.$ and $P_{n}(t)$, respectively].

This underlying structure contributes to the stock of integrated assessment models in several ways. First, it allows the Connecticut (YOHE) Model to expand the range of uncertain driving variables by exhibiting a derived demand for two types of energy defined in part by elasticities of substitution which are not constrained to equal unity. Equation (2.1) also allows uncertainty about technological change in the supply of energy to be brought to bear directly upon input decisions even as it expands the set of substitution possibilities vis-à-vis other aggregate models. Both of these possibilities were identified as among the most important sources of uncertainty in Nordhaus-Yohe [10], but neither has yet been explored fully in a completely integrated assessment context.

Trajectories for population $[L(t)]$ and neutral technological change $[A(t)]$ are given exogenously by:

$$
L(t)=L_{0} e^{l(t) t}
$$

with

$$
l(t)=\left(1-\delta_{L}\right) l(t-1)
$$

and

$$
A(t)=A_{0} e^{a(t) r}
$$

with

$$
a(t)=\left(1-\delta_{A}\right) a(t-1) .
$$

The capital stock at any point in time $[K(t)]$ and the consumption of fossil and nonfossil fuels $\left[E_{c}(t)\right.$ and $\left.E_{n}(t)\right]$ will be determined endogenously. The cost of warming is given by $\Omega(t)$. According to the Nordhaus structure $[8,9]$ adopted by Cline [1],

$$
\Omega(t)=[1+\Delta(t)]^{-1}
$$

where

$$
\Delta(t)=a[T(t) / 3]^{\theta}
$$

is a function of temperature at time $t[T(t)]^{4}$. It is $\Omega(t)$ that is anchored to aggregate damages associated with the $2.5^{\circ} \mathrm{C}$ increase in global mean temperature that is usually attributed to a doubling of concentrations.

The price of nonfossil fuel is given by

$$
P_{n}(t)=P_{n 0}+P_{0} e^{[h(t)+\zeta(t)] t},
$$

with $h(t)$ representing the rate of technological change in the supply of energy and $\zeta(t)$ reflecting the bias of technological change toward (or away from) nonfossil fuel. The price of fossil fuel is similarly given over time by

$$
P_{c}(t)=P_{c 0}+\left[g_{0}+\left\{\left[g_{1} R(t)\right] /[R-R(t)]\right\} e^{h(t) t}+\tau(t),\right.
$$

with

$$
R(t)=\sum_{i=1}^{t-1} E_{c}(i)
$$

representing cumulative fossil fuel consumption through year $(t-1)$. In addition,

$$
\tau(t)=\tau_{0} z(t) e^{r t}+\tau_{d}(t) z(t)
$$

summarizes a range of the carbon tax policy options denominated in dollars per ton of carbon emissions. In writing equation (2.9), $z(t)$ is taken as the carbon content of fossil fuel burned in year $t$. It is applied first to a tax anchor $\left[\tau_{0}\right]$ to produce an emissions reduction shadow price that grows over time at a rate equal to an appropriate rate of discount $[r]$. This first term uses the standard Hotelling result to reflect, from a demand side perspective, an efficient allocation over time whenever cumulative emissions are to be constrained beyond the power of the second $\tau_{d}(t)$ term ${ }^{5}$. The carbon content factor is also applied in this second term, a term designed to modify the Hotelling trajectory to accommodate how the

4 Other structures may be employed in lieu of equation (2.5) as more understanding of potential damages is generated. As it stands, now, the parameters $a$ and $\theta$ are determined by the estimated annual loss (in terms of percent of global GDP) that might be associated with an effective doubling of atmospheric carbon concentrations and some conjecture about how quickly those damages might be climbing at that (future) point in time. Cline [1] and Nordhaus [9] adopt a quadratic structure with doubling causing GDP to fall by 1.3 and $a=0.013$. Note, again, that this damage structure is not employed in the threshold analysis that follows.

5 Manne et al. [7] consider two tax schemes which let an initial shadow price set for the year 1990 rise at a $5 \%$ rate of interest; their motivation is the same as the one which supports the scarcity rent interpretation of $\tau_{0}$ recorded here. 
marginal damage associated with emissions might change over time. Taken together, the two parts of equation (2.9) are constructed to weigh dynamic economic efficiency in the "demand" for constrained carbon emissions over time with a dynamic portrait of their marginal damage and the shadow price of meeting any additional constraint.

To see that equation (2.9) handles a wide range of possibilities, note that it could be used to model efficient allocation over time if $\tau_{d}(t)$ were framed to reflect how (people thought that) the marginal damage of carbon emissions might change over time along a specific, regulated scenario of how the future might unfold. A constant $\tau_{d}(t)$ would be appropriate, for example, if the marginal damage of carbon emissions were thought not to change over time; but $\tau_{d}(t)$ would not be constant if the marginal damage of emissions were seen by most to climb over time as emissions feed into higher and higher atmospheric concentrations of greenhouse gases. Meanwhile, note that $\tau_{0}=0$ unless the targeted constraint on cumulative emissions continued to be binding even along a trajectory regulated by $\tau_{d}(t)>0$; i.e., $\tau_{0}=0$ unless cumulative emissions are to be reduced beyond the level justified by the efficient reaction over time to $\tau_{d}(t)$. Such is nearly always the case when concentrations are to be limited below specified thresholds.

Input decisions in any year conform to the neoclassical fundamentals which set the marginal products inputs equal to their real, net input prices. Full employment over the very long term means that equation (2.2) always holds. Applying these fundamentals to capital, then

$$
K(t)=\{[\gamma \Omega(t-1) x(t-1)] /[(r+\delta)]\},
$$

where $\delta$ represents the applicable rate of depreciation. Investment in any year $t[I(t)]$ must now cover not only depreciation, but also any net investment required to bring $K(t-1)$ up to the level $K(t)$ given in equation (2.10); i.e.,

$$
\begin{aligned}
I(t) & =K(t)-K(t-1)+\delta K(t-1) \\
& =K(t)-(1-\delta) K(t-1)
\end{aligned}
$$

summarizes investment - the portion of GDP devoted each year to maintaining the appropriate capital stock ${ }^{6}$. Applying the same marginal product rules to energy,

$$
E_{n}(t)=\left\{[(1-\gamma-d(t)-\alpha) \Omega(t-1) x(t-1)] /\left[P_{n}(t)\right]\right\}
$$

and

$$
\begin{aligned}
E_{c}(t) & =\left\{\left[\alpha P_{n}(t)\right] /\left[(1-\gamma-d(t)-\alpha) P_{c}(t)\right]\right\} E_{n}(t) \\
& =\left\{[\alpha \Omega(t-1) x(t-1)] /\left[P_{c}(t)\right]\right\}
\end{aligned}
$$

characterize the derived demands for energy consistent with the production schedule given in equation (2.1).

Following the usual convention of imposing the savings equals investment conditions for macroeconomic equilibrium, per capita consumption $[c(t)]$ is

$$
c(t) \equiv[\Omega(t) X(t)-I(t)] / L(t) .
$$

Per capita consumption is known because equations (2.2), (2.10), (2.12) and (2.13) combine with equation (2.1) to set GDP $[X(t)]$ and equation (2.11) sets investment $[I(t)]$. Assuming that utility displays constant relative risk aversion [denoted by $\eta$ ] in per capita consumption, then

$$
U(c(t))=\left[c(t)^{\eta+1}\right] /[\eta+1],
$$

and the de facto optimization envisioned in the construction of the optimal policy seeks to maximize the discounted sum of $U(c(t))$.

The damage side of the model is driven by emissions. Following the DICE construction,

$$
\Gamma(t)=z(t) E_{c}(t),
$$

where

$$
z(t)=\left(1+g_{z}(t)\right) z(t-1)
$$

and

$$
g_{z}(t)=\left(1-\delta_{z}\right) g_{z}(t-1) .
$$

Emissions are converted into atmospheric carbon concentrations $[M(t)]$ by

$$
M(t)=\beta \Gamma(t)+\left(1-\delta_{M}\right) M(t-1) .
$$

In writing equation (2.16), parameter $\beta$ is the instantaneous airborne fraction for carbon and $\delta_{M}$ reflects a seepage factor. The DICE accommodation of the Schneider forcing model completes the portrait. Forcing $[F(t)]$ is, more specifically, represented by

$$
F(t)=4.1\{[\log (M(t) / 590)] / \log (2)\}+O(t),
$$

where $O(t)$ represents other forces; they are, for the moment, taken to be exogenous. The temperature index $[T(t)]$ upon which damages depend in equation (2.5) is related finally to forcing through the now standard two equation simplification of complex global climate models:

$$
\begin{aligned}
T(t)= & T(t-1)+\{F(t)-\lambda T(t-1) \\
& \left.-\left(R_{2} / \tau_{12}\right)\left[T(t-1)-T^{*}(t-1)\right]\right\} / R_{1}
\end{aligned}
$$

and

$$
T^{*}(t)=T^{*}(t-1)+\left\{T(t-1)-T^{*}(t-1)\right\} / \tau_{12},
$$

where the $T^{*}(t)$ variable reflects ocean temperature ${ }^{7}$. 
Sources of uncertainty - parameter location and specification.

\begin{tabular}{|c|c|c|c|c|}
\hline & Description & Location & Specification & Likelihood \\
\hline \multirow[t]{3}{*}{$(1)^{a}$} & Population & Equation (2.2b) & $l(t)=(0.873) l(t-1)$ & $0.25 \mathrm{H}$ \\
\hline & & & $l(t)=(0.805) l(t-1)$ & $0.50 \mathrm{M}$ \\
\hline & & & $l(t)=(0.732) l(t-1)$ & $0.25 \mathrm{~L}$ \\
\hline \multirow[t]{3}{*}{$(2)^{b}$} & Technological change & Equations (2.6) & $h(t)=0.01$ & $0.25 \mathrm{H}$ \\
\hline & in energy supply & and (2.7) & $h(t)=0.0$ & $0.50 \mathrm{M}$ \\
\hline & & & $h(t)=-0.01$ & $0.25 \mathrm{~L}$ \\
\hline \multirow[t]{3}{*}{$(3)^{c}$} & Depletion factor in & Equation (2.7) & $g_{1}=145 \& R=21$ & $0.25 \mathrm{H}$ \\
\hline & fossil fuel price & & $g_{1}=687 \& R=21$ & $0.50 \mathrm{M}$ \\
\hline & & & $g_{1}=1230 \& R=21$ & $0.25 \mathrm{~L}$ \\
\hline \multirow[t]{3}{*}{$(4)^{d}$} & Interfuel elasticity of & Equation (2.1) & $\sigma=-0.4 \& \alpha=-1.50$ & $0.25 \mathrm{~L}$ \\
\hline & substitution $\left[\sigma_{c n}\right]$ & & $\sigma=-0.7 \& \alpha=-0.43$ & $0.50 \mathrm{M}$ \\
\hline & & & $\sigma=-1.2 \& \alpha=0.17$ & $0.25 \mathrm{H}$ \\
\hline (5) & $\begin{array}{l}\text { General technological } \\
\text { change }\end{array}$ & Equation (2.3b) & $a(t)=(0.89) a(t-1)$ & median \\
\hline (6) & Carbon content factor & Equation (2.15) & $g(t)=(1.039) g(t-1)$ & median \\
\hline$(7)^{b}$ & $\begin{array}{l}\text { Technological bias } \\
\text { toward fossil fuel }\end{array}$ & Equation (2.6) & $\xi(t)=0.0$ & median \\
\hline$(8)^{g}$ & $\begin{array}{l}\text { Energy/labor elasticity } \\
\text { of substitution }\left[\sigma_{E L}\right]\end{array}$ & Equation (2.1) & $\sigma=-1.2$ & median \\
\hline$(9)^{h}$ & $\begin{array}{l}\text { Marginal airborne } \\
\text { fraction }\end{array}$ & Equation (2.16) & $\beta=0.64$ & median \\
\hline
\end{tabular}

a Growth rates per decade begining in 1990 with 5.16 billion people and based on an initial annual growth rate of 2.03\%; source: Nordhaus and Yohe [10] and Nordhaus [9].

b Rate of change per year; source: Nordhaus and Yohe [10].

c Reflection of depletion of the high resource estimate in Nordhaus and Yohe [10] fit to reflect the 1993 IEW poll results.

d Measure of the percentage change in fuel mix (fossil to nonfossil) associated with each 1 percent change in relative energy prices; source: Nordhaus and Yohe [10].

c Rate of change per decade beginning in 1990 with a unitless calibrating value of 483 and based on an initial annual growth rate of $1.85 \%$; source: Nordhaus and Yohe [10] and Nordhaus [9].

f Carbon emission per metric ton of coal equivalent with an initial value of 0.688 ; source: Nordhaus [9].

g Measure of the percentage change in energy consumption in proportion to labor employment associated with each 1 percent change in the relative price of energy with respect to the wage paid to labor; source: Nordhaus and Yohe [10].

h Source: Nordhaus and Yohe [10] and Nordhaus [9].

\section{Identification of representative scenarios}

Table 1 highlights nine uncertain parameters over which preliminary Monte Carlo simulation was conducted and indicates the sources of their initial distributions. In each case, high, middle and low values were assigned subjective probabilities of $0.25,0.50$ and 0.25 , respectively. Subsequent modeling focused on the four parameters that contributed most to the range of estimates of emissions through to 2100; the full set of values for these are recorded first ${ }^{8}$. Median values only are noted for the other five. These medians combined with the baseline parameterizations of equations (2.15) through (2.19) from DICE to solidify the foundation for an exhaustive, probabilistically weighted sampling over the other four that adequately reflected the initial Monte Carlo outcomes of 500 randomly selected scenarios drawn from the larger set of $3^{9}$ possible combinations.

The resulting 81 scenarios were ranked in order of

8 Note that technological change in energy $[h(t)]$ and the elasticity of substitution between fossil and nonfossil fuel against energy, as in the original Nordhaus-Yohe [10] work, is among the most significant sources of uncertainty. emissions (in 2100) and partitioned into seven groups. Following a methodology for selecting "interesting" scenarios described in Yohe [16], these partitions were defined and representative scenarios were selected in a way that minimized the probabilistically weighted sum of the squared errors in emissions (again, in 2100) involved in describing the entire distribution by a collection of only seven trajectories ${ }^{9}$. Figures 1 and 2 portray the selected emissions and concentration paths of scenarios (1), (3) [the median trajectory] and (7) graphi-

9 The procedure that leads to the selection of seven representative trajectories also creates a specific partition of all possible trajectories - partitions that were also defined by the minimizing procedure. The procedure starts with an arbitrary partitioning for which error minimizing representatives were chosen. In the next step, the highest member of the lowest partition was moved to the next highest partition and the calculations redone. If the sum of squared errors fell, then another member was moved up; if not, then it was returned to the lowest partition. This trial and error method was applied to all of the partition boundaries until no more error reducing moves were available. There are theorems that describe when this procedure converges to a unique outcome. Their conditions appear to have been met by the collection of 81 emissions values, but confidence can be placed on the fact that starting from different initial partitions and working from both the bottom up and the top down produced the same results. 


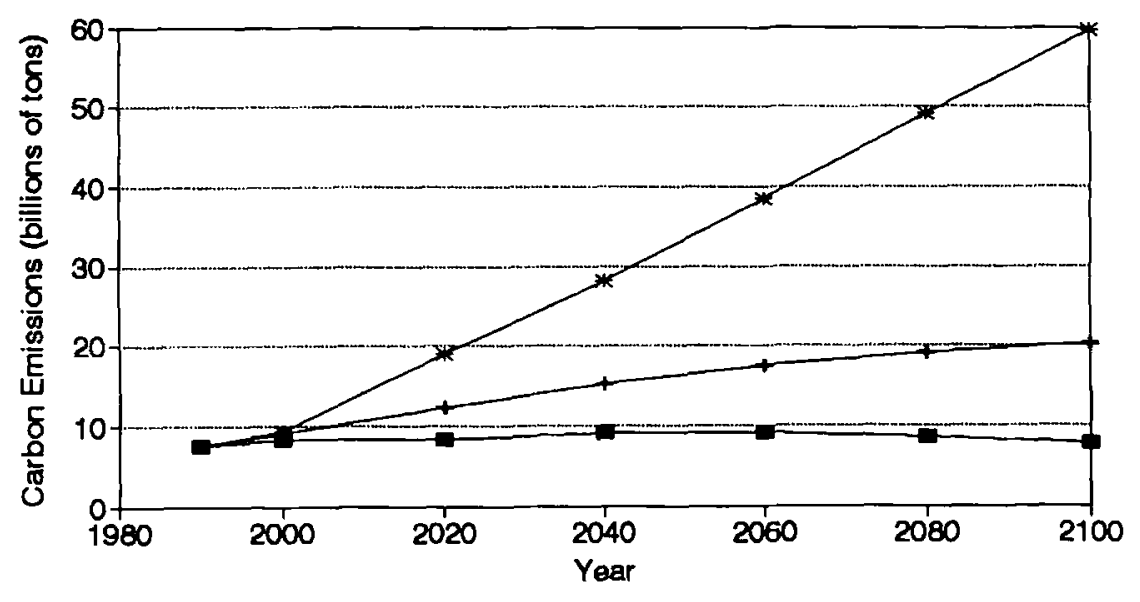

Scenario (1) $\rightarrow$ Scenario $(3) *-$ Scenario $(7)$

Figure 1. Representative emission trajectories.

cally, and table 2 identifies the underlying specifications of all seven alternatives. The probabilities noted in column (1) are the sum of the likelihood weights of all of the scenarios housed in the indicated partition.

Since the scenarios described in table 2 emerged from a process that artificially collapsed a potential of $3^{9}$ runs from one specific model into a manageable set of scenarios deemed representative and "interesting", it is reasonable to question the degree to which they reflect anything more than the idiosyncracies of the model, the selection process, or both. Table 3 performs the dangerous task of comparing these seven scenarios, expressed in terms of both carbon emissions and carbon dioxide concentrations, to several other ranges. It is comforting to note that the seven representative scenarios chosen here do reasonably well in reflecting the diversity of expert opinion. They fully span the emissions recorded by the IPCC in its six specified scenarios; indeed, approximately $20 \%$ of the likelihood range reported here exceeds the highest IPCC emission trajectory (IS92e). The seven selected here lie between the 10th and 90th percentile DICE results in both emissions and concentrations, but they show much more potential on the "high side" than the preliminary "modeler's choice" sample from EMF-14 10 .

There are two other issues of idiosyncracy that can also be explored by comparing results obtained here with those of other modelers. The first concerns the very aggregate nature of the model. Given, particularly, the

${ }^{10}$ See Weyant $[11,12]$ for preliminary EMF-14 results.

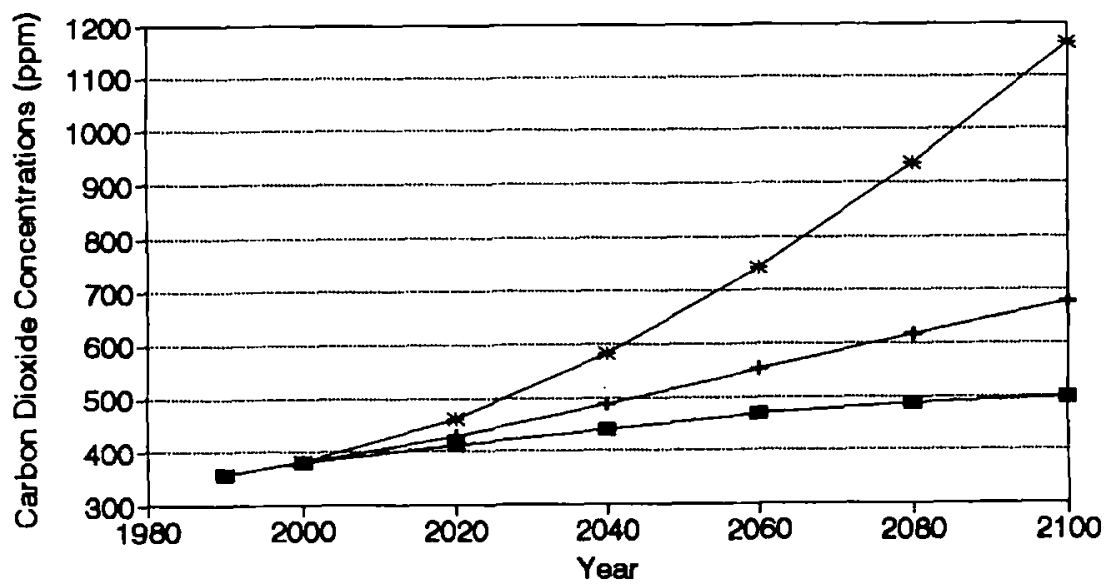

Scenario $(1) \multimap$ Scenario $(3) \rightarrow-$ Scenario $(7)$

Figure 2. Representative concentration scenarios. 
Table 2

Specification of representative scenarios.

\begin{tabular}{|c|c|c|c|c|c|}
\hline Scenario & $\begin{array}{l}\text { Subjective } \\
\text { likelihood }\end{array}$ & $\begin{array}{l}\text { Population } \\
\text { growth }\end{array}$ & $\begin{array}{l}\text { Technological } \\
\text { change }\end{array}$ & Depletion & $\begin{array}{l}\text { Substitution } \\
\text { elasticity }\end{array}$ \\
\hline (1) & 0.27 & $\mathbf{H}$ & $\mathrm{H}$ & L & $\mathbf{H}$ \\
\hline (2) & 0.13 & $\mathbf{H}$ & $\mathbf{M}$ & $\mathbf{M}$ & $\mathbf{H}$ \\
\hline (3) & 0.23 & $\mathbf{H}$ & $\mathrm{L}$ & $\mathbf{H}$ & $\mathbf{H}$ \\
\hline (4) & 0.19 & $\mathbf{M}$ & $\mathbf{M}$ & L & $\mathbf{M}$ \\
\hline (5) & 0.09 & $\mathrm{~L}$ & L & $\mathbf{H}$ & $\mathrm{L}$ \\
\hline (6) & 0.05 & $\mathrm{H}$ & $\mathrm{L}$ & $\mathbf{M}$ & L \\
\hline (7) & 0.04 & $\mathrm{H}$ & $\mathbf{L}$ & $\mathrm{L}$ & $\mathbf{L}$ \\
\hline
\end{tabular}

consolidation of all types of fossil fuel into one variable whose price is driven by equation (2.7), what can be said about the degree to which the costs reflected here conform to costs that might be captured more accurately by models that contain more detail in their energy components? Put another way, how much is lost with the smooth price trajectory dictated by equation (2.7) when the world price will certainly ratchet up a "stair-step" trajectory as relatively scarce fuel-types give way to relatively abundant alternatives?

Results from the median trajectory [scenario (3)] have been reported to the EMF-14 exercise, so comparisons are possible for a number of critical statistics along controlled paths designed to limit atmospheric concentrations to $550 \mathrm{ppm}$ - a particularly good place to focus since this paper ultimately worries about limiting concentrations anywhere from $550 \mathrm{ppm}$ through 850 $\mathrm{ppm}^{11}$. The carbon tax trajectory derived for scenario (3), for example, tracks the path quoted in the second round EMF-14 report from MERGE very well through to 2040 , but then takes a lower route until they again coincide in 2100 . Close coincidence with the reported CETA tax portrait holds through to 2060 ; and through

$"$ See, again, the graphical reports of EMF-14 preliminary results in Weyant $[11,12]$.

Table 3

Selected results-comparisons with conventional wisdom ${ }^{\mathrm{a}}$.

\begin{tabular}{|c|c|c|c|}
\hline & & Emissions in 2100 & Concentrations in 2100 \\
\hline \multirow[t]{9}{*}{ (A) } & Representative scenarios & & \\
\hline & Median inputs & 20.2 & 679 \\
\hline & Scenario(1) & 7.8 & 502 \\
\hline & Scenario (2) & 15.6 & 615 \\
\hline & Scenario (3) & 20.2 & 679 \\
\hline & Scenario (4) & 28.7 & 785 \\
\hline & Scenario (5) & 43.4 & 972 \\
\hline & Scenario (6) & 48.9 & 1044 \\
\hline & Scenario (7) & 59.9 & 1165 \\
\hline \multirow[t]{7}{*}{ (B) } & IPCC scenarios & & \\
\hline & Scenario IS92c & 4.6 & $\mathrm{n} / \mathbf{a}$ \\
\hline & Scenario IS92d & 9.9 & $\mathrm{n} / \mathbf{a}$ \\
\hline & Scenario IS $92 b$ & 18.6 & $\mathrm{n} / \mathrm{a}$ \\
\hline & Scenario IS $92 a$ & 19.8 & $\mathrm{n} / \mathrm{a}$ \\
\hline & Scenario IS $92 \mathrm{f}$ & 25.9 & $\mathrm{n} / \mathrm{a}$ \\
\hline & Scenario IS92e & 34.9 & $\mathrm{n} / \mathrm{a}$ \\
\hline \multirow{4}{*}{ (C) } & $\mathrm{DICE}^{\mathbf{b}}$ & & \\
\hline & $\begin{array}{l}\text { DICE }^{b} \\
\text { Tenth percentile }\end{array}$ & & \\
\hline & $\begin{array}{l}\text { Tenth percentile } \\
\text { Median trajectory }\end{array}$ & 6.4 & $\begin{array}{l}465 \\
671\end{array}$ \\
\hline & $\begin{array}{l}\text { Median trajectory } \\
\text { Ninetieth percentile }\end{array}$ & $\begin{array}{l}24.1 \\
82.5\end{array}$ & $\begin{array}{r}671 \\
1203\end{array}$ \\
\hline \multirow[t]{5}{*}{$(D)^{c}$} & Energy Modeling Forum - 14 & & \\
\hline & Modeler's choice (low) & 8.5 & 605 \\
\hline & Modeler's choice (high) & 32.0 & 1150 \\
\hline & Standardized reference (low) & 12.0 & 605 \\
\hline & Standardized reference (high) & 48.5 & 1550 \\
\hline
\end{tabular}

\footnotetext{
a Emissions are given in billions of metric tons of carbon; concentration is parts per million volume.

b Values reported for 2095, actually, in table 7.3 of Nordhaus [9].

${ }^{c}$ Values estimated from graphical presentations of First Round EMF-14 results.
} 
to 2100 against the results of the highly disaggregated MIT model. Estimates of a second statistic defined to quantify the cost of abatement generally fell near the middle of first round EMF-14 citations through to 2100 (after they begin to diverge in roughly 2040). Indeed, by the year 2100 , the estimate of global control costs of $\$ 3740$ billion derived from scenario (3) lies squarely in the middle of a range reported to EMF-14 that runs from more than $\$ 7000$ billion from CETA on the high side down to PAGE's roughly $\$ 1000$ billion on the low side. Finally, discounting the loss in world GDP associated with restricting concentrations along scenario (3) to 550 ppm $5 \%$ produces an estimate of approximately $\$ 19$ trillion - a value that closely matches results of a similar discounting procedure produced from MER GE ${ }^{12}$.

The second area of concern about the specifics of the model is derived from its simplistic treatment of the carbon cycle. Equations (2.16) through (2.19) capture that treatment; and they have been drawn directly from the DICE formulation. Other simple representations exist (see, e.g., Maler-Reimer and Hasselmann [5]) and have been employed by other researchers to investigate issues of timing, among other things (see, e.g., Wigley et al. [14]); and many feel that these representations produce more credible portraits of targeted emissions and concentration trajectories because they more closely approximate the complexities of the underlying science. These concerns are well founded, of course, but comfort can be taken in observing that the targeted emissions and concentration trajectories reported here look much more like trajectories produced by Wigley et al. than they do the more suspect IPCC trajectories. This point can be supported by again focusing on scenario (3) - this time because it tracks IPCC BaU emissions scenario (IS92a) quite closely. In restricting concentrations to no more than $550 \mathrm{ppm}$ from the IS92a baseline, the IPCC reports concentrations of $450 \mathrm{ppm}$ and $525 \mathrm{ppm}$ for 2050 and 2100 , respectively. Wigley and his colleagues show that emissions can rise more quickly in the near term even when a $550 \mathrm{ppm}$ threshold is imposed and report concentrations of approximately $480 \mathrm{ppm}$ and $530 \mathrm{ppm}$ for the same dates ${ }^{13}$. Meanwhile, the work produced here will show coincident concentrations of $470 \mathrm{ppm}$ and $540 \mathrm{ppm}$ along the restricted scenario (3) trajectory. The match is not exact, but the proximity suggests that using the more dated carbon-cycle representation of the DICE framework is not too expensive.

Comparison with even a full set of alternative scenarios would not constitute validation of these scenarios, to be sure. There is, nonetheless, some convincing evidence that the seven scenarios described in table 2 do, indeed, adequately span the range of current opinion about what the future might hold and that their underly-

12 See Manne et al. [7].

13 Approximate figures read from figure 1 in Wigley et al. [14]. ing structure does not produce anomalous cost or concentration statistics.

\section{Limiting concentrations for representative scenarios}

Equation (2.9) provides the analytical means with which to reduce emissions by taxing carbon along any scenario so that concentrations converge on any prescribed limit from below. If the given limit cannot be determined until sometime in the future, however, policies that must be imposed prior to that time can be too strict or too lenient, depending upon the limit that is ultimately identified. Excessively stringent early taxes increase near term control costs even though they reduce costs in the more distant future; and early taxes that turn out to be too lenient impose smaller near term losses at the expense of excessive downstream costs. Either type of error can be costly, therefore, even considering long term adjustments, and so the immediate policy decision involved in setting short term emissions taxes is really determined by minimizing the expected present value of total costs computed to include the excess cost attributable to either type of error in all states of nature.

To see exactly what is involved in this minimization, let the stream of taxes designed to hold concentrations below threshold $i$ along scenario $j$ be given by $\left\{{ }_{j} \tau_{i k}(t)\right.$ \} when the appropriate limit turns out to be threshold $k$. Meanwhile, let the discounted value of the control cost associated with each tax be $\left\{{ }_{j} C_{i k}\right\}$. These statistics can be expressed as the sum of the usual (discounted) dead weight loss triangles ${ }^{14}$. If the present view of the likelihood that threshold $k$ will be prescribed were $\pi_{k}$, then

$$
E\left\{{ }_{j} C_{i}\right\} \equiv \sum_{k} \pi_{k j} C_{i k}
$$

would be the expected cost of setting initial taxes targeted at achieving threshold $i$ along scenario $j$.

Table 4 records the results of an experiment that explores the ramifications of equation (4.1) along the seven scenarios identified in section 3 for a $3 \%$ discount rate. It was produced assuming that the correct concentration limit will be one of seven possible choices $(550$ ppm, $600 \mathrm{ppm}, \ldots, 850 \mathrm{ppm}$ ). Each was thought to be equally likely in 1995 but it is assumed that the true and actual target will be found among them and announced in the year 2020. The question is thus one of determining what series of taxes from 1995 through 2020 minimizes $E\left\{{ }_{j} C_{i}\right\}$ along each scenario assuming precise, cost-minimizing mid course corrections in the tax series in the year $2020^{15}$.

14 See chapter 4 in Nordhaus [9] for a complete description of these deadweight loss measures.

is The runs were all initialized to 1990 , but policies were invoked in 1995. 
Table 4

Summary statistics for equally likely concentration thresholds. The expected present cost of control through $2200^{\mathrm{a}}$.

\begin{tabular}{llllllll}
\hline $\begin{array}{l}\text { Assumed } \\
\text { threshold }\end{array}$ & \multicolumn{2}{l}{ Scenario number } & & & \\
\cline { 2 - 7 } & $(1)$ & $(2)$ & $(3)$ & $(4)$ & $(5)$ & $(6)$ & $(7)$ \\
\hline 550 & 0.00 & 0.77 & 2.33 & 5.69 & 22.39 & 26.17 & 33.31 \\
600 & 0.00 & 0.77 & 2.15 & 5.66 & 21.74 & 25.54 & 32.77 \\
650 & 0.00 & 0.77 & 2.07 & 5.66 & 21.46 & 25.28 & 32.52 \\
700 & 0.00 & 0.76 & 2.02 & 5.64 & 21.31 & 25.18 & $32.49^{*}$ \\
750 & 0.00 & 0.67 & 2.00 & 5.64 & 21.25 & 25.17 & 32.60 \\
800 & 0.00 & 0.67 & 1.98 & 5.64 & 21.22 & $25.16^{*}$ & 32.65 \\
850 & $0.00^{*}$ & $0.67^{*}$ & $1.97^{\circ}$ & $5.64^{*}$ & $21.21^{*}$ & 25.18 & 32.69 \\
\hline
\end{tabular}

a These are the $E\left\{{ }_{j} C_{i}\right\}$ of equation (4.1). They are denominated in percent of world GNP in 1990; one percentage point is approximately $\$ 210$ billion.

The statistics presented in table 4 actually report expected costs through to 2200 as a percentage of 1990 world GDP (1 point is approximately $\$ 210$ billion) ${ }^{16}$. The starred values highlight the smallest expected costs. They suggest that setting taxes with the expectation that $850 \mathrm{ppm}$ will turn out to be correct minimizes expected costs for scenarios (1) through (5). Scenario (6) supports $800 \mathrm{ppm}$ as the best target; and scenario (7), $700 \mathrm{ppm}$. High emission trajectories can lead to high initial taxes targeted at intermediate concentration thresholds, but the conclusion that shooting for the least restrictive 850 ppm target is remarkably robust. Table 5 records the appropriate taxes for representative years between 1995 and 2020 - taxes associated with the expected cost minimizing threshold targets just identified.

\section{Limiting concentrations with uncertain scenarios}

Concentration targets are not the only source of uncertainty facing the global policy community. Global deci-

16 Comparisons of the transient control costs that support the statistics recorded in table 4 show that more than eighty percent of the probability (scenarios (1) through (4)) span the costs recorded in the First Round of EMF-14. Preliminary results reported in Round 2 capture the costs associated with scenarios (5) and (6), as well.

Table 5

Expected cost minimizing taxes for representative scenarios ${ }^{\mathrm{a}}$.

\begin{tabular}{lcccc}
\hline Scenario & Best target & \multicolumn{3}{c}{ Carbon tax for selected years } \\
\cline { 3 - 5 } & & 1995 & 2000 & 2010 \\
\hline$(1)$ & 850 & 0.00 & 0.00 & 0.00 \\
$(2)$ & 850 & 0.00 & 0.00 & 0.00 \\
$(3)$ & 850 & 0.05 & 1.00 & 4.35 \\
$(4)$ & 850 & 0.64 & 1.79 & 5.34 \\
$(5)$ & 850 & 8.15 & 11.90 & 19.00 \\
$(6)$ & 800 & 11.70 & 16.67 & 25.48 \\
$(7)$ & 700 & 22.94 & 31.88 & 45.99 \\
\hline
\end{tabular}

a Taxes here are identified for selected years between 1995 and 2020 that are defined as the beginning tax trajectories designed to meet the indicated best target along the identified scenario; thresholds are assumed to be equally likely. sion makers now have least (expected) cost tax trajectories for each scenario through to 2020 , but they are still unsure about which scenario will most closely represent the future. As a result, they still face a set of "too high versus too low" errors within which to weigh an ultimate decision. A little more notation can sort through the combinations and permutations that emerge even given the enormous simplification of table 5 .

Assume, now, that all uncertainty will be resolved in 2020 ; i.e., suppose that the appropriate concentration limit and the actual future scenario will be determined by 2020. Let $\left\{{ }_{j l} \tau_{i k}(t)\right\}$ represent the series of taxes that minimizes the present value of control cost if:

(1) scenario $j$ were anticipated in 1995 ,

(2) scenario $l$ were determined to be most representative in 2020 ,

(3) taxes associated in table 5 with scenario $j$ and targeted at limit $i$ were imposed through 2020, and

(4) limit $k$ turned out to be correct.

There would, with such a series, be a control cost series whose present value is now represented by $\left\{{ }_{j l} C_{i k}\right\}$. Recalling that $\pi_{j}$ represents the likelihood (viewed in 1995) that limit $j$ will emerge as the most appropriate, let $\pi^{l}$ be the likelihood (viewed in 1990) that scenario $l$ will turn out to be the most representative. Based upon the Monte Carlo results that support this analysis, the appropriate $\pi$ are given in the first column of table 2 .

The expected value of choosing the initial taxes from table 5 that are targeted at threshold $i$ (anticipating scenario $j$ ) can now be expressed as

$$
E\left\{{ }_{j l} C_{i k}\right\} \equiv \sum_{k} \pi_{k}\left\{\sum_{l} \pi_{j l}^{l} C_{i k}\right\} .
$$

Table 6 shows the results of these calculations (again control costs through to 2200 based on deadweight loss triangles and again expressed in terms of percentage points of 1990 world GDP). The first seven columns show the terms in the right hand sign bracket for each 
Table 6

Summary statistics for equally likely concentration thresholds. The expected cost of scenario defined control through 2200 with scenarios weighted by modeling results ${ }^{\mathrm{a}}$.

\begin{tabular}{|c|c|c|c|c|c|c|c|c|}
\hline \multirow{2}{*}{$\begin{array}{l}\text { Initial } \\
\text { target and } \\
\text { defining } \\
\text { trajectory }\end{array}$} & \multicolumn{7}{|c|}{ Expected costs across scenarios by target } & \multirow{2}{*}{$\begin{array}{l}\text { Expected } \\
\text { value }\end{array}$} \\
\hline & $(550)$ & $(600)$ & $(650)$ & (700) & $(750)$ & $(800)$ & $(850)$ & \\
\hline $850(1 \& 2)$ & 16.51 & 12.99 & 5.94 & 4.02 & 2.84 & 2.42 & 1.59 & $6.62^{*}$ \\
\hline $850(3)$ & 16.40 & 12.96 & 6.07 & 4.17 & 3.02 & 2.61 & 1.79 & 6.72 \\
\hline $850(4)$ & 16.69 & 13.16 & 6.10 & 4.20 & 3.06 & 2.65 & 1.82 & 6.81 \\
\hline $850(5)$ & 16.50 & 13.15 & 6.45 & 4.61 & 3.49 & 3.08 & 2.27 & 7.08 \\
\hline $800(6)$ & 16.43 & 13.16 & 6.61 & 4.79 & 3.68 & 3.28 & 2.47 & 7.20 \\
\hline $850(7)$ & 16.40 & 13.30 & 7.09 & 5.32 & 4.24 & 3.84 & 3.05 & 7.61 \\
\hline
\end{tabular}

a The seven columns are the $\sum \pi^{l}\left\{{ }_{l} C_{i k}\right\}$ of equation (4.2). The last column records the resulting complete $E\left\{{ }_{j l} C_{i k}\right\}$. They are all denominated in percent of world GNP in 1990; one percentage point is approximately $\$ 210$ billion.

limit and anticipated scenario (through 2020) for the $\pi$ of table 2. The last column records the corresponding expected values given a uniform prior across prospective limits.

The remarkable result is that planning for $850 \mathrm{ppm}$ by imposing the zero taxes associated with scenarios (1) and (2) minimizes the expected present value of control cost; i.e., the costs of over-reacting early always dominate even when there is no benefit side to consider. These are costs of meeting non-economically imposed and nonetheless binding thresholds; and so the result is not driven by a low benefit side. Indeed, the benefit side is a policy imperative - a concentration standard with whatever shadow price is required to make it stick.

Table 7 examines the gross sensitivity of these conclusions to changes in the weighting of the representative scenarios. The values recorded there were computed under the assumption that all of the scenarios were equally likely. The effect of this assumption is to move 21 points of likelihood from below scenario (4) to above scenario (4) and to increase the likelihood of scenarios (6) and (7) by factors of 3 . The procedure is dramatic, placing more than $45 \%$ of likelihood above highest IPCC scenario. The least (expected) cost choice is now to target $850 \mathrm{ppm}$ under the presumption that scenario (3) will turn out to be most descriptive of the future. This is a change in policy perspective, to be sure, but the early taxes still only climb from $\$ 0.05$ in 1990 to $\$ 4.35$ in 2010 - remarkably modest taxes under severely distorted assumptions.

\section{Concluding remarks}

The specific analysis reported here shows that little or no emissions reduction is warranted over the near term even as a hedge against the possibility of having to meet severely binding concentration limits sometime in the not too distant future. This is a striking result, given the enormous uncertainty reflected here in both the future path of carbon emissions and the range of possible concentration limits. The specifics are not to be believed, of course. They depend critically upon the model offered. It is an aggregate model, so it misses much detail whose inclusion might have changed some of the numbers. Comparison with the results of more detailed models suggests, however, that the qualitative conclusions should not be too suspect in this regard. The model also depends upon a specific and simplified representation of the carbon cycle that might also be the source of some concern. Again, comparison suggests that the errors are not too large, especially in the near term (the real focus

Table 7

Summary statistics for equally likely concentration thresholds. The expected cost of scenario defined control through 2200 with equally weighted scenarios ${ }^{\mathrm{a}}$.

\begin{tabular}{|c|c|c|c|c|c|c|c|c|}
\hline \multirow{2}{*}{$\begin{array}{l}\text { Initial } \\
\text { target and } \\
\text { defining } \\
\text { trajectory }\end{array}$} & \multicolumn{7}{|c|}{ Expected costs across scenarios by target } & \multirow{2}{*}{$\begin{array}{l}\text { Expected } \\
\text { value }\end{array}$} \\
\hline & $(550)$ & $(600)$ & $(650)$ & $(700)$ & (750) & $(800)$ & $(850)$ & \\
\hline $850(1 \& 2)$ & 31.43 & 25.21 & 12.76 & 8.94 & 6.49 & 5.57 & 3.74 & 13.45 \\
\hline $850(3)$ & 31.24 & 25.10 & 12.83 & 9.03 & 6.63 & 5.38 & 2.89 & $13.30^{*}$ \\
\hline $850(4)$ & 31.55 & 25.32 & 12.85 & 9.06 & 6.66 & 5.75 & 3.92 & 13.59 \\
\hline $850(5)$ & 31.14 & 25.11 & 13.06 & 9.35 & 6.99 & 6.09 & 4.30 & 13.72 \\
\hline $800(6)$ & 30.97 & 25.04 & 13.17 & 9.49 & 7.15 & 6.26 & 4.47 & 13.79 \\
\hline $850(7)$ & 30.69 & 24.96 & 13.49 & 9.91 & 7.61 & 6.73 & 4.97 & 14.05 \\
\hline
\end{tabular}

a The seven columns are the $\sum \pi^{l}\left\{{ }_{i l} C_{i k}\right\}$ of equation (4.2). The last column records the resulting complete $E\left\{{ }_{i l} C_{i k}\right\}$. They are all denominated in percent of world GNP in 1990 ; one percentage point is approximately $\$ 210$ billion. 
of the work); in fact, moving to alternative carbon cycle representations that support higher emissions early would underscore the qualitative conclusions offered here that only modest intervention is appropriate over that near term.

It must be emphatically noted that this qualitative conclusion is not derived from the usual cost-benefit paradigm where low market-based damages, vague nonmarket damages, and the unrecognized potential of significant irreversible results undermine the need for strong and immediate emission controls. In fact, the imposition of nonmarket criteria for avoiding a significant impact of global change was taken to be clear, decisive, unquestioned; indeed, it was drawn from outside the economic paradigm. All that the analysis asked of the economic analysis was that the path to be chosen to avoid the potential impact be as cost-effective as possible.

The work reported here certainly begs the question of when and whether the modeled scientific certainty might emerge. A twenty-five year time frame has been imposed, but what if it were longer? The results reported in tables 6 and 7 are so robust that it is difficult to tell a story that might explain why extended uncertainty might alter near term policy; but the growing divergence of concentration trajectories beyond 2020 offers the suggestion that tradeoffs cast between limiting concentration thresholds and across alternative emissions scenarios would cut more deeply in (e.g.) a learning period between 2020 and 2045 or 2050 . Even as this hypothesis is explored, though, a qualitative message of near term response can be offered. Fundamental research into both the concentration thresholds of serious potential impacts (or some other observable metric of change that might signal those impacts) and the likely trajectories of emissions and concentrations could pay substantial dividends. The first defines a broad agenda of natural scientific issues. The latter identifies a social science agenda and highlights several critical foci: technological change in the supply of energy, the ability to substitute nonfossil fuels for fossil fuels, population and its distribution across the globe, and the degree to which depletion of fossil fuels is reflected in its real price. It would appear that global decision makers could honestly buy themselves some time if they chose to pursue both with some directed intensity.

\section{Acknowledgements}

This work was funded by the U.S. Department of Energy. The authors acknowledge the assistance offered by participants of EMF-14 and the unusually thorough and thoughtful comments provided by two anonymous referees. The paper is better because of their input. They also acknowledge the contribution of David South who offered wise and productive input even during some dif- ficult times. Finally, the authors thank Wesleyan students who double-checked all of the modeling calculations as part of their work in an environmental economics class. As a result, clearly, all remaining errors remain with the authors.

\section{References}

[1] W. Cline, The Economics of Global Warming, Institute for International Economics, Washington, 1992.

[2] A. Dixit and R. Pindyck, Investment Under Uncertainty, Princeton University Press, Princeton, NJ, 1994.

[3] J. Edmonds, R. Richels and M. Wise, Future fossil fuel carbon emissions without policy intervention: A review, in: Proceedings of the 1993 Global Change Institute on the Carbon Cycle, Snowmass, Colorado, 1994.

[4] Intergovernmental Panel on Climate Change (IPCC), Climate Change 1992: The Supplemental Report to the IPCC Scientific Assessment, Cambridge University Press, Cambridge, UK, 1992.

[5] E. Maler-Reimer and K. Hasselmann, Transport and storage of $\mathrm{CO}_{2}$ in the ocean: An inorganic ocean-circulation carbon cycle model, Climate Dynamics 2, 1987, 63-90.

[6] A. Manne and R. Richels, Buying Greenhouse Insurance: The Economic Costs of Carbon Dioxide Emissions, MIT Press, Cambridge, Massachusetts, 1994.

[7] A. Manne, R. Mendelsohn and R. Richels, MERGE - A Model for Evaluating Regional and Global Effects of GHG reduction policies, Stanford University mimeo, Stanford, California, November 1993.

[8] W. Nordhaus, An optimal transition path for controlling greenhouse gases, Science 258, November 1992, 1315-1319.

[9] W. Nordhaus, Managing the Global Commons: The Economic of Climate Change, MIT Press, Cambridge, Massachusetts, 1994.

[10] W. Nordhaus and G. Yohe, Future carbon dioxide emissions from fossil fuels, in: Changing Climate, National Academy Press, Washington, 1983.

[11] J. Weyant, First Round Preliminary Results: Energy Modeling Forum - 14, Stanford University Press, Stanford, California, September 1994.

[12] J. Weyant, Second Round Preliminary Results: Energy Modeling Forum - 14, Stanford University Press, Stanford, California, May 1995.

[13] J. Weyant (lead author), Integrated assessment of climate change: An overview and comparison of approaches and results, Chapter 10 in the Report of Working Group III, Intergovernmental Panel on Climate Change, forthcoming.

[14] T. Wigley, R. Richels and J. Edmonds, Alternative emissions pathways for stabilizing $\mathrm{CO}_{2}$ concentrations, Nature, forthcoming.

[15] G. Yohe, Constant elasticity of substitution production functions with three or more inputs, Economics Letters 15, 1983, 29-34.

[16] G. Yohe, Toward a general methodology for selecting "interesting" greenhouse scenarios, Climate Research 1, 1991, 169-177.

[17] G. Yohe, J. Neumann and H. Amaden, Assessing the economic cost of greenhouse induced sea level rise: Methods and application in support of a national survey, Journal of Environmental Economics and Management 29, 1995, S-78-S-98.

[18] G. Yohe, J. Neumann, P. Marshall and H. Amaden, The economic cost of greenhouse induced sea level rise for developed property in the United States, Climatic Change, 1996. 